Review

\title{
Perspectives on the integration of students with disabilities in physical education: An umbrella review of reviews published between 2010 and 2020
}

Andreas Fröberg

Received: $23^{\text {rd }}$ July 2020; Accepted: $14^{\text {th }}$ January 2021; Published: $11^{\text {th }}$ July 2021

\begin{abstract}
Research regarding the integration of students with disabilities in physical education has progressively increased during the last three decades, as has the number of published reviews. The objective of this umbrella review was to synthesise findings from reviews published between 2010 and 2020 to obtain a comprehensive picture of the current literature regarding the integration of students with disabilities in physical education. Search strings were developed and the four electronic databases Educational Research Complete, ERIC, Scopus, and SportDiscus were searched to identify reviews published between January 2010 and January 2020. After removing duplicates, 117 individual documents were screened and reviewed for eligibility, and eight reviews published between 2012 and 2019 were included. These reviews included quantitative, qualitative, and mix methods research. From the reviews, to some degree, SWDs, SWODs and PETs have mixed experiences from and ambiguous attitudes towards the integration of SWDs in PE.
\end{abstract}

Keywords: Inclusion; inclusive education; special needs; school

\section{Introduction}

The educational benefits claimed for physical education (PE) include the physical, cognitive, social, and affective domains (Bailey, 2005; Bailey et al., 2009). In PE, students might experience positive social interactions with peers and teachers, learn to cooperate, and demonstrate empathy and respect (e.g., Bailey et al., 2009; Beni, Fletcher, \& Ní Chróinín, 2017; Opstoel et al., 2019). Until today, PE has been dominated by a multi-activity based curriculum with much focus on sport and sport techniques (Penney, Jeanes, O'Connor, \& Alfrey, 2018; Tinning, 2012). Compared to the regular classroom, the PE environment is, therefore, characterised by physical activity (e.g., Hollis et al., 2016; 2017), and many activities require peer-collaboration as part of, for example, peer-assisted learning (Ward \& Lee, 2005). Similar to the regular classroom, however, PE teachers (PETs) meet groups of students with different physical, social, and cognitive needs, skills, and abilities.

Global estimates suggest that approximately five per cent of young individuals and 15 percent of the world's population live with some form of disability (World Health Organization, WHO, 2015). Disability might be understood and defined differently depending on the disability discourse. While there are several different models of disability available (Degener, 2016), Haegele and Hodge (2016) discuss that, in general, two models of disability discourse are prominent in contemporary society: the medical model and the social model. In the narrative of the medical model, a disability is an impairment of the body 
function and structure which deviates from the norm and that is subject to medical intervention and in need of treatment (to be cured, fixed, or rehabilitated). Here, exclusion from societies is an individual problem that is attributed to the disability. To some extent, the medical model also infers that barriers related to disabilities are not contextual but instead universal and something that can be translated across different contexts (e.g., Degener, 2016; Grenier, 2010; Haegele \& Hodge, 2016). Furthermore, individuals with disabilities have been associated with negative stereotypes, and the medical model has been subject for criticism because of, for example, labelling and treatment of individuals with disabilities, and the negative perceptions of disability that are embedded therein (e.g., Bunbury, 2019; Grenier, 2010). The medical model of disability might also have implications for human rights because it might, for example, legitimise segregated facilities for individuals with disabilities, such as special schools (Degener, 2016).

Based on ideas embedded in the disabled people's movement, Oliver (1983; 1990) introduced the social model in the 1980s-1990s. Although researchers have suggested different roles for the social model (see, e.g., Levitt, 2017), Oliver (2013) viewed the social model as a practical tool that might be used to change peoples' lives for the better. Nonetheless, through the social model, disability is "regarded as a mere difference within the continuum of human variations" (Degener, 2016, p. 3). It, furthermore, distinguishes between an impairment and a disability. An impairment is understood as the condition of body function and structure, whereas a disability is understood as the environmental response to the impairment.

In contrast to the medical model, where exclusion from societies is an individual problem that is attributed to the disability, the social model focuses on the societal barriers and the disadvantages or restrictions that, through discrimination and oppression, occur in the interaction between the impairment and the wider external environment (e.g., Bunbury, 2019; Degener, 2016; Haegele \& Hodge, 2016). By focusing on societal barriers, the social model draws attention to and challenges attitudes and perceptions that exist in the disability discourse (e.g., Bunbury, 2019). From this point of view, schools and teachers need to adopt practices to ensure that all students experience a sense of belonging in the educational context (e.g., Grenier, 2007; 2010). In line with the ideas embedded within the social model, the WHO currently uses disability as an umbrella term for

impairments, activity limitations and participation restrictions, denoting the negative aspects of the interaction between an individual (with a health condition) and that individual's contextual (environmental and personal) factors. (WHO, 2015, 1)

Moreover, inclusive education has received widespread attention during the last decades (Hernández-Torrano, Somerton, \& Helmer, 2020; Van Mieghem, Verschueren, Petry, \& Struyf, 2018). Consensus about inclusive education was reached at the International Conference on Education in the late 2000s, (UNESCO, 2008), and has been acknowledged as one guiding principle for provision of quality PE policy and practice (UNESCO, 2015). Even though inclusive education historically has been conceptualised as education for students with disabilities (SWDs; UNESCO, 2020), the importance of inclusive and equitable quality education for all students has been recognised as part of the shared goals, political priorities and ambitions of the Sustainable Development Agenda 2030 (United Nations, 2015). Accordingly, inclusive education not only encompasses SWDs (albeit the foci in this paper) but all students, regardless of gender identity and expression, ethnicity, religion, disability or other bases for discrimination (UNESCO, 2020). Nonetheless, SWDs 
might be particularly at risk of experiencing exclusionary practices in educational contexts (UNESCO, 2020).

The interpretation of the multidimensional concept of inclusive education remains, however, somewhat ambiguous (Göransson \& Nilholm, 2014; Haug, 2017). For example, Göransson and Nilholm (2014) found four qualitatively different definitions of the concept inclusion that ranged from inclusion as the physical placement of SWDs in the general classroom to inclusion as the creation of communities in schools and classrooms.

In a broad sense, this paper embraces the definition of inclusion and inclusive education as recently used by UNESCO. In their report, UNESCO defined inclusion as a "process consisting of actions and practices that embrace diversity and build a sense of belonging, rooted in the belief that every person has value and potential and should be respected" ( $p$. 419). This definition indicates that inclusion has an important subjective dimension. This thought process aligns with findings reported by Spencer-Cavaliere and Watkinson (2010). They explored inclusion in PE from the perspectives of SWDs. They found that interactions and relationships with peers, such as feeling like a legitimate participant and having friends, were important to feel included.

Moreover, UNESCO (2020) defined inclusive education as an, "education that promotes mutual respect and value for all persons and builds educational environments in which the approach to learning, the institutional culture and the curriculum reflect the value of diversity" (p. 420).

Inclusive education is thus not merely a matter of physically placing SWDs in the regular classroom. As argued by Haegele (2019), a conceptual distinction should be made between integration and inclusion. Whereas integration represents the physical placement in which students are educated, inclusion might be regarded as a philosophy that reflects the rights of all students to experience a sense of belonging and acceptance within the classroom. One step towards realising inclusive education is to view diversity as an opportunity to be celebrated, and teachers need to be prepared to teach all students and possess attitudes and knowledge that allows every student to succeed (UNESCO, 2020). In this regard, it is critical to acknowledge that "[c]urriculum, pedagogy, assessment and the design of a school or classroom may be more or less enabling, more or less disabling” (Slee, 2018, p. 9).

In the last few decades, there has been a growing interest regarding the integration of SWDs in PE. Previous research suggests that SWDs sometimes engage in activities in which they are taught separately from students without disabilities (SWODs; e.g., Smith \& Thomas, 2006). Furthermore, research indicates that SWDs have experienced not only social isolation but also discrimination from SWODs and PETs (e.g., Block \& Obrusnikova, 2007; Coates \& Vickerman, 2008; O’Brien, Kudláček, \& Howe, 2009). From a teacher perspective, research suggests that PETs perceive themselves as having limited experiences from integrated PE, and that they do not feel adequately prepared to teach SWDs (e.g., Coates \& Vickerman, 2008). Overall, previous research, therefore, indicates that, although integrated into PE, SWDs do not always feel included.

There has been a steady growth of research regarding the integration of SWDs in PE. There is reason to believe that the number of reviews has increased simultaneously. Although there are several motives and methodological approaches to comply with a review, the aim is generally to map research activity and merge existing knowledge (Sutton, Clowes, Preston, \& Booth, 2019). Reviews that have different focuses and analytical procedures might report different findings and arrive at different conclusions. It is, therefore, useful to conduct a review of reviews (an umbrella review) to determine the current state of the literature (Aromataris et al., 2015). So far, there has been no attempt to synthesise findings of recent reviews focusing on the integration of SWDs in PE from a student and a teacher 
perspective. However, an umbrella review would provide a comprehensive picture of the current literature within the research field. Therefore, the objective of this umbrella review was to synthesise findings from reviews published between 2010 and 2020. In doing so, this umbrella review focuses on the perspectives of students and teachers on the integration of SWD in PE and, more specifically, experiences, attitudes, and representation. Available recommendations guided the process of developing, conducting, and reporting this umbrella review (Aromataris et al., 2015).

\section{Materials and Methods}

\section{Inclusion criteria}

To be included, the reviews could be labelled as narrative or systematic reviews, scoping reviews, meta-syntheses, and meta-analyses (see Sutton et al., 2019, for an overview of different review types), which all have their individual characteristics, strengths and limitations (Grant \& Booth, 2009). To guarantee the comprehensiveness, however, the reviews had to encompass searches in at least three electronic databases, keywords and inclusion criteria explicitly stated. Both reviews summarising quantitative and qualitative research from a student and a PET perspective were included. It was assumed that reviews published over the past ten years would include both older and newer research. Therefore, only reviews published between 2010 and 2020 were considered for inclusion. In addition, the reviews were required to be published in a peer-review English-language journal.

As research on the integration of SWDs in PE mostly concern human experience and social phenomenon, the Population, phenomenon of Interest, and Context (PICo) elements (Stern, Jordan, \& McArthur, 2014) were used to formulate the following broad inclusion criteria: 1) SWDs, SWODs, and PETs (Population); 2) experiences, attitudes, and representation (the phenomenon of Interest), and 3) school PE (Context). Reviews (or parts thereof) focusing on SWODs were thus also included in this paper. However, findings related to other stakeholders' perspectives (e.g., PET educators or parents) were beyond the objective of this paper and excluded. Reviews that explicitly included only theoretical perspectives and opinion statements as the key source of literature were also excluded.

\section{Electronic database search}

The four electronic databases Educational Research Complete, ERIC, Scopus, and SportDiscus were searched to identify relevant reviews. Together, these electronic databases covered education sciences (Educational Research Complete and ERIC), social sciences (Scopus), and various aspects of sport and exercise sciences, such as medicine, psychology, and education (SportDiscus). The search strings shown in Appendix Table A were developed with support from two university librarians. The keywords reflected population (e.g., "student*" and "pupil*"), context (e.g., "physical education"), and study type (e.g., "review*" and "meta-synthes*"). The searches were limited to title, abstract and keywords, and English language documents published in peer-review journals between January 2010 and January 2020. Furthermore, reference lists of all documents that met the inclusion criteria were manually checked to identify additional reviews of relevance.

\section{Summary approach and data extraction}

The search results were exported from the electronic database into EndNote (version X9, Clarivate Analytics) software for managing and citing the references. After removing duplicates, titles and abstracts of the identified documents were reviewed and checked against the inclusion criteria. After that, full-text copies of all potentially relevant documents were retrieved, reviewed for eligibility, and included if meeting the inclusion criteria. The 
flow of information through the different phases of this process was presented in a Preferred Reporting Items for Systematic Reviews and Meta-analyses guidelines (PRISMA) flow-chart (Moher, Liberati, Tetzlaff, \& Altman, 2009).

\section{Summary approach}

At an initial stage, the reviews were read multiple times to become familiar with the focus, analytical procedure, and the overall findings. After that, an in-depth reading and narrative analysis of the overall findings was conducted, returning to the identified reviews, as necessary. In this process, the main findings were qualitatively synthesised by seeking and identifying patterns across the reviews. The findings that shared similar features were categorised into sub-themes (when appropriate) and themes (Patton, 2015). Although these sub-themes and themes should be understood as inter-related, they reflected the overall interpretation of the main findings presented within each theme. Throughout the summary approach, the main focus was on the individual and the microsystem of the ecological theoretical framework. In this case, the microsystem was understood as the immediate environment (Bronfenbrenner, 1979), in which students and teachers interact with each other in school and PE. In the final stage, each theme was descriptively labelled based on the overall content.

During the summary approach, it became evident that terms such as "inclusion" and "inclusive physical education" frequently have been used in previous reviews. As previously argued, however, there is a conceptual distinction between integration (physical placement) and inclusion (a sense of belonging and acceptance within a group; see, e.g., Haegele, 2019). In this paper, the term "integration" was used because it says something about the physical placement of SWD but which, at the same time, does not necessarily indicate whether they actually experience a sense of belonging and acceptance in integrated PE.

Furthermore, although researchers have different preferences for terminology when reporting studies involving students with various disabilities (Peers, Spencer-Cavaliere, \& Eales, 2014), the broad term "disability" and the people-first language (i.e., "students with disabilities") were used throughout this paper. "Disability" was chosen because most recent reviews had used this term, and because it acknowledges that disabilities denote the negative aspects of the interaction between an individual and that individual's contextual factors. Furthermore, the people-first language was chosen because it recognises students beyond their attributes, and because it might reduce inappropriate generalisations.

\section{Data extraction}

The following data was extracted to a table to provide an overview of the reviews: 1) citation details; 2) primary objective; 3) type of review; 4) perspective(s) (SWDs, SWODs and PETs); 5) the number of databases searched (year range) and studies included, and 6) instrument used to appraise the studies (i.e., rating of their quality; yes/no). The synthesised findings for each review were extracted to another table.

\section{Methodological quality assessment}

The methodological quality of the reviews was assessed using the critical appraisal checklist for systematic reviews and research syntheses (Aromataris et al., 2015). The critical appraisal checklist features ten items each scored as either "Met" (1 point), "Not met", "Unclear", or "Not applicable" (o points each). The higher the total score, the better the overall methodological quality. 


\section{Results}

As shown in Figure 1, the initial electronic database search resulted in 193 documents. After removing duplicates, 117 individual documents were screened and reviewed for eligibility. Of these, full-text of nine documents were read and eight reviews were included.

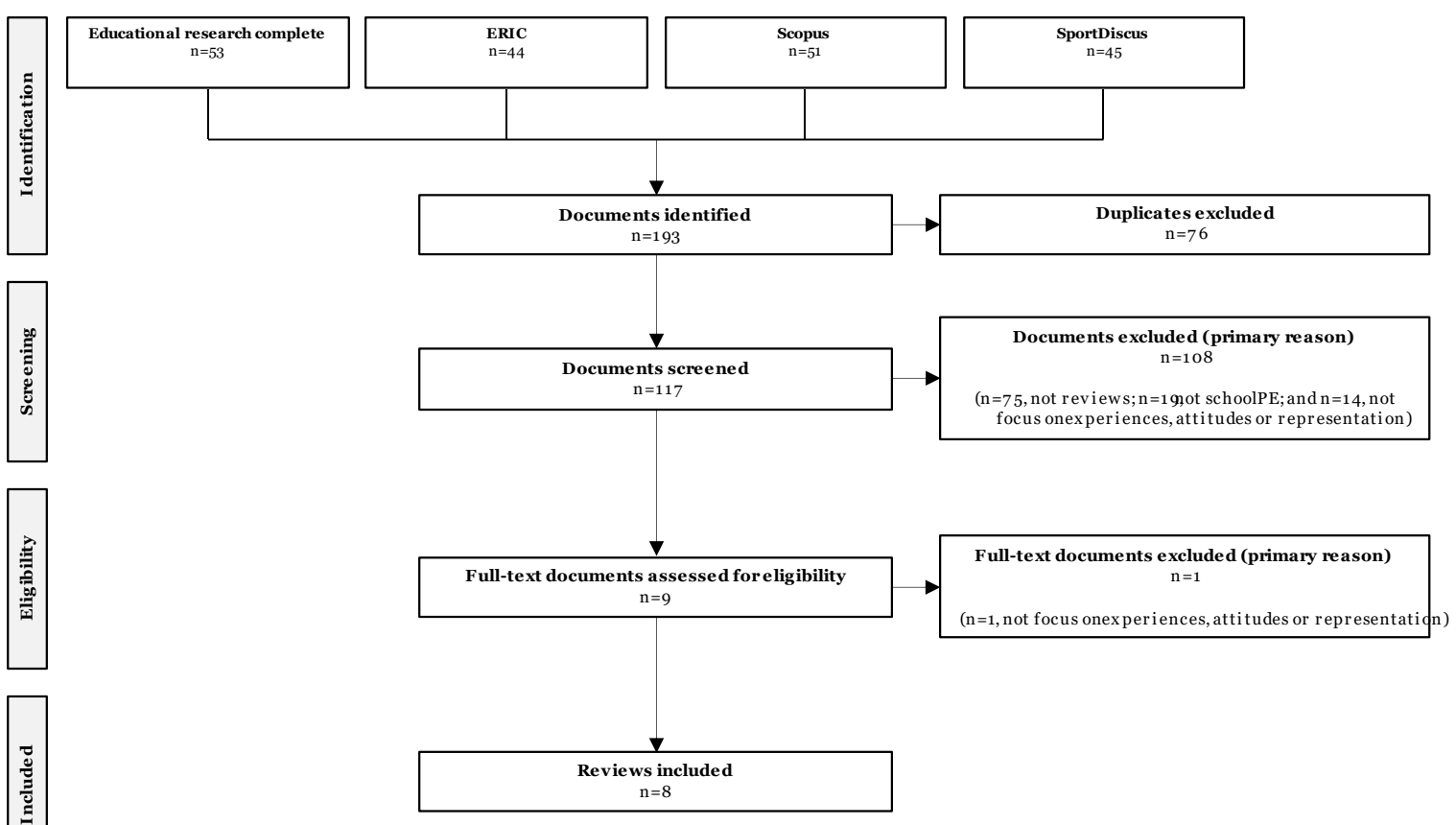

Figure 1. The PRISMA flow-chart.

Table 1 presents the characteristics of the reviews. The eight reviews were published between 2012 and 2019. Three were labelled as systematic reviews, two as reviews, one as a narrative review, and the remaining two as a qualitative meta-analysis and qualitative inquiry review, respectively. Together, the reviews covered quantitative and qualitative research or mixed methods research. Two focused on a student perspective, two on a teacher perspective, and four on both a student and a teacher perspective. The number of studies included in the reviews ranged from ten to 112, and the research reported were conducted in Africa, North and South America, Asia, Europe, and Oceania or mixed. However, most research was conducted in North America and Europe. The original studies reviewed were published between 1979 and 2017. The reviews covered studies that, directly or indirectly (e.g., hypothetical scenarios such as attitude questionnaires), explored perspectives on students with various disabilities such as physical, emotional-behavioural, attentionlearning, and learning disabilities.

All reviews were judged as of moderate-to-high methodological quality (7-8 out of 10 points) (Appendix Table B). The synthesised findings of the reviews are presented below and in Table 2. The summary approach generated in two themes for SWDs, two themes for SWODs, and five themes for PETs.

\section{Students with disabilities}

The most repeated finding was that experiences from, and attitudes towards integration into PE seems mostly negative from the viewpoints of SWDs. Simultaneously, however, SWDs have also reported some positive experiences from integration into PE. The summary approach generated the two themes i) participation and ii) support and interaction. 
Table 1. Characteristics of the reviews

\begin{tabular}{|c|c|c|c|c|c|}
\hline Citation details & Primary objective & Type of review & Perspective(s) & $\begin{array}{l}\text { The number of databases } \\
\text { searched (year range) and } \\
\text { studies included }\end{array}$ & $\begin{array}{l}\text { Instrument } \\
\text { used to } \\
\text { appraise } \\
\text { the studies } \\
\text { (yes/no) }\end{array}$ \\
\hline $\begin{array}{l}\text { Haegele \& } \\
\text { Sutherland } \\
(2015)\end{array}$ & $\begin{array}{l}\text { To review published qualitative inquiries to examine the } \\
\text { perspective of SWDs towards their experience in PE }\end{array}$ & $\begin{array}{l}\text { Qualitative } \\
\text { inquiry review }\end{array}$ & SWDs & $\begin{array}{l}\text { Ten databases (1995-2014) } \\
\text { and } 13 \text { studies }\end{array}$ & No \\
\hline $\begin{array}{l}\text { Hutzler et al. } \\
\text { (2019) }\end{array}$ & $\begin{array}{l}\text { To provide a narrative summary of international research } \\
\text { perspectives and findings regarding PETs' attitudes and } \\
\text { self-efficacy toward inclusion }\end{array}$ & Narrative review & PETs & $\begin{array}{l}\text { Three databases (unclear) } \\
\text { and } 75 \text { studies }\end{array}$ & No \\
\hline $\begin{array}{l}\text { Pocock \& } \\
\text { Miyahara } \\
\text { (2018) }\end{array}$ & $\begin{array}{l}\text { To aggregate and analyse existing qualitative studies to } \\
\text { answer the primary research question: What are the } \\
\text { perceptions of PETs and SWDs on teaching and learning } \\
\text { experiences within inclusive PE at primary and } \\
\text { secondary schools? }\end{array}$ & $\begin{array}{l}\text { Qualitative meta- } \\
\text { analysis }\end{array}$ & SWDs and PETs & $\begin{array}{l}\text { Seven databases (2000-2016) } \\
\text { and } 12 \text { studies }\end{array}$ & No \\
\hline Qi \& Ha (2012) & $\begin{array}{l}\text { To analyse empirical studies on inclusion in PE over the } \\
\text { past } 20 \text { years and then propose recommendations for } \\
\text { future research }\end{array}$ & Review & $\begin{array}{l}\text { SWDs, SWODs, } \\
\text { and PETs }\end{array}$ & $\begin{array}{l}\text { Six databases (1990-2009) } \\
\text { and } 75 \text { studies }\end{array}$ & No \\
\hline $\begin{array}{l}\text { Rekaa et al. } \\
(2019)\end{array}$ & $\begin{array}{l}\text { To review and synthesise knowledge from research on } \\
\text { actual experiences of inclusion }\end{array}$ & Systematic review & SWDs and PETs & $\begin{array}{l}\text { Eight databases (unclear) } \\
\text { and } 27 \text { studies }\end{array}$ & Yes \\
\hline $\begin{array}{l}\text { Ruscitti et al. } \\
\text { (2017) }\end{array}$ & $\begin{array}{l}\text { To identify, summarise and critically analyse primary } \\
\text { literature that explores the effects of inclusive PE classes } \\
\text { on SWODs }\end{array}$ & Review & SWODs & $\begin{array}{l}\text { Three databases (1975-2015) } \\
\text { and ten studies }\end{array}$ & Yes \\
\hline $\begin{array}{l}\text { Tant \& Watelain } \\
\text { (2016) }\end{array}$ & $\begin{array}{l}\text { To systematically list the international studies about the } \\
\text { inclusion of SWDs in PE from the PETs' perspective }\end{array}$ & Systematic review & PETs & $\begin{array}{l}\text { Eight databases (1975-2015) } \\
\text { and } 60 \text { studies }\end{array}$ & No \\
\hline $\begin{array}{l}\text { Wilhelmsen \& } \\
\text { Sørensen (2017) }\end{array}$ & $\begin{array}{l}\text { To compile, organise, and analyse the body of literature } \\
\text { on inclusion of SWDs in PE }\end{array}$ & Systematic review & $\begin{array}{l}\text { SWDs, SWODs, } \\
\text { and PETs }\end{array}$ & $\begin{array}{l}\text { Four databases (2009-2015) } \\
\text { and } 112 \text { studies }\end{array}$ & Yes \\
\hline
\end{tabular}


Table 2. Synthesised findings of the reviews

\section{Citation details \\ Haegele \&}

Sutherland

(2015)

\section{Synthesised findings (selected)}

\section{Student perspective}

SWDs have experienced positive (e.g., support, consensual and caring) and negative (e.g., bullying, feelings of social isolation, and negative social comparisons) peer interactions. Interactions with PETs either positively or negatively affected SWDs' perspectives towards participating in PE. Some students with invisible disabilities have experienced marginalisation only when disclosing their disability. Inclusion and exclusion processes are somewhat uncontrollable from the perspective of SWDs. Three types of exclusion/inclusion processes were identified: 1) forced exclusion where SWDs are excluded from activities by external means (e.g., constraints imposed by instructional space); 2) forced inclusion where SWDs are forced to participate which might have negative effects (e.g., SWDs may question their own ability to participate); and 3) selfexclusion where SWDs seek exclusion because of, for example, fear of being injured, sensory issues, and negative experiences of forced inclusion, and a feeling of being different).

PET perspective

Not applicable.

Hutzler et al. Student perspective

(2019) Not applicable.

PET perspective

PET-factors related to attitudes towards integration of SWDs in PE show somewhat mixed results for sex (although there is a tendency towards females being more positive), age, and amount and quality of acquaintance with SWDs. Those with less professional experience tend to have more positive attitudes. However, some studies suggest that those with more training that is academic and those with higher self-perceived competence had more positive attitudes. Some studies also indicate that PETs have less positive attitudes toward integrating older SWDs and students with emotional or behavioural disabilities.

\section{Pocock \& Student perspective}

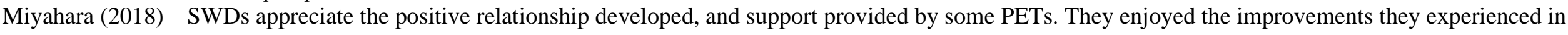
appropriately planned lessons that enabled participation. Some have been instructed to complete tasks in isolated contexts. In addition, some perceive their PETs to hold lower expectation to them compared to SWODs.

PET perspective

Teaching practices contributing to inclusion included: 1) expression of creativity in adapting teaching methods, equipment and environment; 2) sharing knowledge between teachers, specialists, parents and SWDs to increase their understanding of how to teach SWDs; 3 ) having the needs of the SWDs at the foreground when developing lessons; and 4) spending considerable time and effort planning and reflecting on lessons and teaching practices. Individualised instruction was an occasional necessity to meet the individual needs of SWDs, generate a positive experience for all students, and encourage full classroom participation. PETs frequently reported separating SWDs from SWODs to perform a distinct activity in isolated contexts. Some PETs have faced time constraints when developing lessons and modifying activities for SWDs. SWDs were sometimes required to integrate into existing lessons (rather than having the lessons modified). The lack of confidence, comfortability and certainty PETs have led to difficulties in integrating SWDs. More difficult to promote integration during complex activities such as sporting 


\section{Citation details $\quad$ Synthesised findings (selected)}

games. Some PETs are uncomfortable when adapting and modifying activities, rules, instructions and equipment. PETs held lower expectations

of SWDs and did not hold them accountable for their actions. PE was seen by some PETs as an arena for SWDs to acquire physical skills to enable participation in physical activity and sports.

Qi \& Ha (2012) Student perspective

SWDs have positive (e.g., friendships might develop) and negative (e.g., social isolation) experiences. SWODs who are females, younger, and those who had experiences with a family member or close friend with a disability have more positive attitudes. Interventions on disability awareness programs have reported mixed findings.

PET perspective

PETs have more positive attitudes toward teaching students with learning disabilities (compared to emotional and behavioural disabilities) and those with mild disabilities (compared to severe). Female PETs, those with more experience with SWDs, more academic preparation, and higher self-perceived competence, have more positive attitudes. Potentially facilitating factors include professional preparation, perceived competence, previous teaching experiences, and available school support. Inhibiting factors include lack of in-service training, inadequate preparation, and the type and severity of the disabilities of students.

Rekaa et al. Student perspective

(2019) SWDs have positive (e.g., having/making friends and supportive interactions with SWODs) and negative (e.g., limited/restricted participation, and social isolation) experiences from PE. It might be challenging for SWDs to have/maintain an identity as a physically active individual. SWDs needed to feel as legitimate participants who contributed to the game. SWDs seem to be excluded from competitive activities, and they have a hard time when they have to sit and watch/do different activities than SWODs. The behaviour of PETs is crucial for SWDs' experiences. PET perspective

PETs have positive and negative experiences from, and attitudes towards the integration of SWDs in PE. If SWODs are supportive and encouraging, the PETs have more favourable attitudes. PETs feel incompetent in dealing with the needs of SWDs. PETs often highlight practical issues as the main reason for negative experiences. Negative attitudes are also particularly prevalent when it comes to full integration for students with severe impairments that were perceived as highly problematic. Perceptions of possibilities vary between students from different impairment groups (e.g., more negative to the idea of including students with emotional-behavioural and attention-learning disabilities than students with other types of difficulties). PETs' are concerned that SWDs will demand more time (e.g., individualised attention, instruction and support) which might lead to neglect of SWODs. In addition, PETs are concerned that SWDs will disrupt the class by misbehaving, not following instructions or not staying on task, and that this will reduce the quality of PE.

Ruscitti et al. Student perspective

SWODs who are females and those with prior experience of individuals with disabilities might have more positive attitudes towards integration of SWDs in PE. Disability awareness programs can be used to educate about disabilities and facilitate positive attitudes and understanding for the integration of SWDs in PE.

PET perspective

Not applicable. 


\section{Citation details Synthesised findings (selected)}

Tant \& Watelain Student perspective

(2016) Not applicable.

PET perspective

PET-related factors that influence attitude towards integration of SWDs in PE showed no effect or were inconsistent for sex, age, degree earned, experience, or training in APE. Nonetheless, perceived competence in teaching SWDs predicted the PETs' attitude. PETs' attitudes toward teaching SWDs depend on their age (more positive towards younger), the disability label itself, and the type and severity of the disability (more positive toward students with learning disabilities than those with emotional and behavioural disabilities). PETs' representations that are positive towards PE for SWDs is formed by 1) professional training (consistency and quality); 2) exchanges between teachers and colleagues (frequency and quality); 3) adequacy of training and inclusive texts that are open to adapted physical activities and sports for individuals with disabilities.

\section{Wilhelmsen \& Student perspective}

Sørensen (2017) SWDs have positive attitudes when they are given the opportunity for full participation and when they perceive themselves as legitimate participants that contribute to the games. Having or making friends are important positive social experiences. SWDs have experienced bullying. Sport disability programs supported SWODs to question their assumptions about the skills and abilities of individuals with disabilities.

PET perspective

PETs have positive and negative attitudes towards the integration of SWDs in PE. There were mixed results for PETs' sex, education, and teaching experience. Size of class and time constraints were perceived as challenges. PETs have more negative towards teaching students with emotional-behavioural difficulties. PETs might be concerned that SWDs have negative effects on SWODs and whether activities are safe for SWDs, or whether SWODs will accept SWDs. Among facilitating factors are peer acceptance and collaboration with stakeholders such as other professions (e.g., learning support assistants).

Abbreviations: APE, Adapted physical education; PE, Physical education; PET, Physical education teacher; SWDs, Students with disabilities; SWODs, Students without disabilities. 


\section{Theme: Participation}

The theme participation covered two sub-themes that together represented conflicting findings for experiences and attitudes about integration into PE. These two sub-themes were labelled as, restrictions, marginalisation, and exclusion, and, full and legitimate participation, respectively.

\section{Sub-theme: Restrictions, marginalisation, and exclusion}

The findings for the first sub-theme represented negative aspects of integration into PE and demonstrate that, frequently, SWDs have experienced not only restricted participation but also marginalisation and exclusion. For example, SWDs have reported feeling invisible and that their PET has disregarded their needs (Haegele \& Sutherland, 2015). SWDs do not enjoy $\mathrm{PE}$ when they have limited or restricted participation, do different activities than SWODs, or are positioned next to the activities to merely observe the lesson (Rekaa, Hanisch, \& Ytterhus, 2019). Moreover, some SWDs have perceived it challenging to have or maintain an identity as a physically active individual in integrated $\mathrm{PE}$, and this perception might result in embarrassed students (Rekaa et al., 2019).

From the findings, exclusion is common during high-status (competitive) activities, and that the segregated activities that SWDs participate in are perceived to be of less social value (Haegele \& Sutherland, 2015; Rekaa et al., 2019). In addition, that SWDs have been instructed to complete tasks in isolated contexts (Pocock \& Miyahara, 2018).

Moreover, PE activities that are not adapted to meet the needs of SWDs can bring about negative experiences (Haegele \& Sutherland, 2015). In turn, these negative experiences have led SWDs to perceive themselves as unable to participate with SWODs. The following negative experiences might also lead to SWDs requesting or seeking exclusion in PE: perceived differences in abilities between themselves and SWODs, and feelings of being different from SWODs (Haegele \& Sutherland, 2015). Moreover, Haegele and Sutherland (2015) found that some SWDs have experienced forced exclusion through external factors, including constraints imposed by instructional environments, such as challenges in accessing different outdoor activity areas (e.g., wheelchairs in outdoor environments).

\section{Sub-theme: Full and legitimate participation}

In terms of participation, the second sub-theme, full and legitimate participation, represents the positive aspect of integration into PE. Some SWDs who are integrated into PE have reported that their PETs effectively adapt and modify activities appropriate for students with different abilities and skills (Haegele \& Sutherland, 2015). Furthermore, SWDs have positive attitudes towards PE when they are given the opportunity for full participation and when they perceive themselves as legitimate participants that contribute to the games (Rekaa et al., 2019; Wilhelmsen \& Sørensen, 2017).

\section{Theme: Support and interaction}

The summary approach also generated in the theme, support and interaction, that covered two sub-themes. These two sub-themes were labelled as, negative social peer interactions and isolation, and, positive social peer interactions. These themes represent negative and positive aspects related to social support and interaction in integrated PE, respectively.

\section{Sub-theme: Negative social peer interactions and isolation}

From the findings related to the first sub-theme, which also appear to be most prominent, SWDs have experienced negative social peer interaction in integrated PE 
(Haegele \& Sutherland, 2015; Qi \& Ha, 2012; Rekaa et al., 2019; Wilhelmsen \& Sørensen, 2017). These negative social peer interactions include actions and behaviours such as bullying in the form of yelling, name-calling, and violence (Haegele \& Sutherland, 2015; Rekaa et al., 2019; Wilhelmsen \& Sørensen, 2017). In addition to bullying, some SWDs have experienced negative social comparisons in PE. These negative experiences seem to arise when SWDs compare their abilities to their perceptions of the abilities of SWODs (Haegele \& Sutherland, 2015). Also, social isolation of some SWDs has occurred, such as limited or restricted opportunities to interact and communicate with SWODs during activities (Haegele \& Sutherland, 2015; Qi \& Ha, 2012; Rekaa et al., 2019).

\section{Sub-theme: Positive social peer interactions}

Albeit to a lesser extent, the findings related to this second sub-theme show that SWDs have experienced positive social peer interactions in integrated PE. Here, SWDs have experienced practical and emotional support enabling participation. More specifically, they have experienced that SWODs assist with involvement in the activities performed (Haegele \& Sutherland, 2015). From the findings in this sub-theme, SWDs have experienced positive social peer interactions in the form of, for example, consensual and caring interactions (e.g., Haegele \& Sutherland, 2015; Rekaa et al., 2019). Another recurrent finding was that having or making friends are important positive social experiences from integrated PE (e.g., Qi \& Ha, 2012; Rekaa et al., 2019; Wilhelmsen \& Sørensen, 2017).

\section{Students without disabilities}

Findings related to SWODs mostly concerned their attitudes towards the integration of SWDs in PE, and the impact of using sport disability programs to facilitate positive attitudes and educate SWODs about disabilities. The summary approach generated in the two themes, varying attitudes across different peer groups, and, sport disability programs as a pedagogical strategy.

\section{Theme: Varying attitudes across different peer groups}

In terms of attitudes towards the integration of SWDs in PE, this theme represents the varying findings across different peer groups. The findings seem to be somewhat consistent, in that female students, younger students, and students with prior structured and recurring exposer to individuals with disabilities seem to have more positive attitudes towards the integration of SWDs in PE than male students, older students, and those lacking exposure to individuals with disabilities (Qi \& Ha, 2012; Ruscitti, Thomas, \& Bentley, 2017). Ruscitti and colleagues (2017) also found that the adoption of rules and activities might prompt some SWODs to oppose the integration of SWDs in PE.

\section{Theme: Sport disability programs as a pedagogical strategy}

Ruscitti and colleagues (2017) as well as Wilhelmsen and Sørensen (2017) showed that sport disability programs, such as Paralympic school day, might be used to educate SWODs about disabilities, and that such disability programs might support SWODs to question their assumptions about skills and abilities of individuals with disabilities. However, Qi and Ha (2012) reported mixed findings for disability awareness programs on attitudes towards peers with disabilities.

\section{Physical education teachers}

The general interpretation of the findings was that PETs have somewhat mixed experiences from and ambiguous attitudes towards the integration of SWDs in PE. The summary approach generated in the following five themes, i) factors influencing experiences 
and attitudes, ii) knowledge, skills, and comfort, iii) time, spaces, and objects, iv) acceptance and impact on students, and v) teaching practices.

\section{Theme: Factors influencing experiences and attitudes}

Findings indicate that positive attitudes among PETs might be a critical factor in ensuring meaningful experiences among SWDs in integrated PE (Haegele \& Sutherland, 2015). Some findings demonstrate that experiences from, and attitudes towards the integration of SWDs in PE depend on some teacher and student-related factors. The theme, factors influencing experiences and attitudes, covered two sub-themes labelled as, teacherrelated factors, and, student-related factors. These sub-themes represent factors that negatively and positively influenced experiences from, and attitudes towards the integration of SWDs in PE.

\section{Sub-theme: Teacher-related factors}

Findings related to this first sub-theme were somewhat inconsistent for teacher-related factors such as sex, age, education, and teaching experience concerning attitudes (Hutzler, Meier, Reuker, \& Zitomer, 2019; Qi \& Ha, 2012; Tant \& Watelain, 2016; Wilhelmsen \& Sørensen, 2017). In some of the reviews there was a tendency towards female PETs and those with more education, training or teaching experience have more positive attitudes (Hutzler et al., 2019; Qi \& Ha, 2012). In other reviews there were suggestions that the findings are inconsistent for such factors (Tant \& Watelain, 2016; Wilhelmsen \& Sørensen, 2017). In contrast, however, more consistent findings were reported for self-perceived competence. In most studies, higher self-perceived competence to deliver PE among SWDs was related to positive experiences and attitudes (e.g., Hutzler et al., 2019; Qi \& Ha, 2012; Tant \& Watelain, 2016).

\section{Sub-theme: Student-related factors}

From the findings for this second sub-theme, student-related factors might influence experiences from, and attitudes towards the integration of SWDs in PE. PETs seems more positive towards teaching younger SWDs (Hutzler et al., 2019; Tant \& Watelain, 2016). Furthermore, experiences and attitudes seem to depend on the type and severity of the disability (Qi \& Ha, 2012; Rekaa et al., 2019; Tant \& Watelain, 2016). For example, PETs perceive that integration of students with severe impairments is highly problematic (Rekaa et al., 2019). From the findings, PETs are more negative towards teaching students with emotional-behavioural disabilities compared to, for example, learning disabilities or hearing and visual impairments (e.g., Hutzler et al., 2019; Rekaa et al., 2019; Tant \& Watelain, 2016; Wilhelmsen \& Sørensen, 2017).

Moreover, from previous findings, PETs have more experiences and attitudes that are positive when SWODs are supportive and encouraging (Rekaa et al., 2019; Wilhelmsen \& Sørensen, 2017).

\section{Theme: Knowledge, skills, and comfort}

Within the theme, knowledge, skills, and comfort, the findings show that PETs perceive themselves as unprepared to integrate SWDs in PE (e.g., Rekaa et al., 2019). Compared to individual-based activities, PETs also seem to find it more challenging to facilitate inclusion in complex, non-individual activities such as different sport games (Pocock \& Miyahara, 2018). In terms of comfort, Pocock and Miyahara (2018) also reported that some PETs feel uncomfortable when adopting/modifying activities to enable full participation among all students. 
Theme: Time, spaces, and objects

Concerning the theme, time, spaces, and objects, the integration of SWDs in PE was perceived as time-consuming and that PETs have faced time-constrains when planning and delivering PE for SWDs (Pocock \& Miyahara, 2018; Wilhelmsen \& Sørensen, 2017). The size of class, practical issues, and lack of resources have also been reasons for negative experiences from integrated PE (Rekaa et al., 2019; Wilhelmsen and Sørensen, 2017).

\section{Theme: Acceptance and impact on students}

Another theme that was generated from the summary approach was, acceptance and impact on students. According to the reviews, PETs might be concerned whether activities are safe for SWDs and whether SWODs will accept SWDs in integrated PE (Rekaa et al., 2019; Wilhelmsen \& Sørensen, 2017). Furthermore, PETs occasionally separated SWD from SWODs to complete one-on-one instruction as this was deemed most appropriate to facilitate participation and positive experiences among all students (Pocock \& Miyahara, 2018).

Moreover, in some studies, PETs are concerned that integration of SWDs in PE can have negative effects on SWODs. For example, Rekaa et al. (2019) reported that PETs might be worried that they pay less attention to SWODs and that the overall quality of PE might be reduced when SWDs are integrated into PE.

\section{Theme: Teaching practices}

The theme, teaching practices, represent findings related to PETs expression regarding ways to facilitate inclusive practices in integrated PE. In their review, Pocock and Miyahara (2018) found that these teaching practices include the adoption of teaching and instructional strategies, equipment, and the teaching environment. These teaching practices also involved taking own responsibility for gathering information about their students' disability, focusing on the needs of SWDs when developing the lesson, and spending considerable time and effort devoted to preparation, reflection, and evaluation of their teaching practices (Pocock \& Miyahara, 2018).

Furthermore, the teacher also perceived that knowledge sharing and collaboration with stakeholders, such as other PETs and specialists, facilitated inclusion in integrated PE (e.g., Pocock \& Miyahara, 2018). Other findings suggest that using embedded instructions, peertutoring, and cooperative learning might aid inclusion (e.g., Qi \& Ha, 2012; Tant \& Watelain, 2016; Wilhelmsen \& Sørensen, 2017).

\section{Discussion}

This umbrella review synthesised findings from reviews published between 2010 and 2020 to obtain a comprehensive picture of the current literature regarding the integration of SWDs in PE. The eight reviews were judged as of moderate-to-high methodological quality and covered both quantitative and qualitative research that focused on a student and a teacher perspective. Based on the reviews, to some degree, SWDs, SWODs and PETs have mixed experiences from and ambiguous attitudes towards the integration of SWDs in PE. Overall, these findings are similar to those presented in reviews published before 2010 (e.g., Block \& Obrusnikova, 2007; Coates \& Vickerman, 2008; O’Brien et al., 2009; Smith \& Thomas, 2006). Moreover, the contextual conditions, such as the specific student group, PET, and school characteristic, might be crucial for how the integration of SWDs in PE will be experienced.

At the same time, however, the experiences seem mostly negative from the viewpoints of SWDs. These negative experiences appear to arise from several reasons, including 
negative social comparisons, social isolation, and bullying (Haegele \& Sutherland, 2015; Qi \& Ha, 2012; Rekaa et al., 2019). According to the findings in previous reviews, integrated PE might not always provide SWDs with inclusive experiences, such as a sense of belonging and acceptance.

In addition to the above, there is evidence that it might be challenging for SWDs to have or maintain an identity as a physically active individual in integrated PE (e.g., Rekaa et al., 2019). Simultaneously, some PETs might be inclined to focus on sports skills and wish to preserve physical activity instead of exploring how activities can be adapted to become more inclusive (e.g., Pocock \& Miyahara, 2018; Tant \& Watelain, 2016). From the review by Ruscitti and colleagues (2017) not all SWODs might agree or comply with the adoption of rules and games as it might reduce the intensity and quality of PE activities. The fact that some PETs also seems worried that the overall quality of PE might be reduced when SWDs are integrated into PE (Rekaa et al., 2019), and that some perceive it as uncomfortable to adopt activities, instructions, and equipment (Pocock \& Miyahara, 2018), says something about which expectations exist about contemporary PE.

The reason that PETs are inclined to focus on sports skills and that they experience lack of comfortability to adopt teaching practices is likely multifaceted. It might include timeconstraints, and lack of resources, confidence, and knowledge. However, it might also, at least in part, be embedded into the narrow idea of $\mathrm{PE}$ as sports and sport techniques which seem to have dominated the PE discourse since the mid-twentieth century (Tinning, 2012). In a recent review focusing on sociocultural processes of ability, Nabaskues-Lasheras and colleagues (2019) found that merely those students who fit the ideologies of sport and performance might receive recognition in PE. From some of the reviewed studies, certain PE practices are deemed acceptable whereas others are being rejected.

Although, for a long time, researchers have encouraged the transition from the multiactivity based curriculum to embrace a more holistic approach towards physical activity (e.g., Penney \& Jess, 2004), researchers continue to indicate that a rather narrow set of sport-related activities might be legitimated in PE (Nabaskues-Lasheras et al., 2019). In this sense, Rekaa et al. (2019) stated that SWDs might be "fitted into the relatively stable and well-known practice of PE" (p. 52). SWDs who are integrated into PE likely perceive that their bodies and abilities do not adequately fit within the overall idea of PE because of the multi-activity-based curriculum. As a consequence, SWDs might experience feelings of embarrassment and otherness. Coupled with the fact that SWDs seem to experience negative social comparisons, social isolation, and bullying, the effectiveness of integrated PE to meet inclusion agendas seems to be somewhat questionable.

In this context, it seems appropriate to echo the suggestions by Barber (2018), "it is imperative that we educate future $[\mathrm{PE}]$ teachers to be open-minded, have broad definitions of ability and also be skilled at differentiating learning goals, success criteria and activities, while using diverse ways to assess them" (p. 529).

Suppose inclusion in PE is to become a reality, not only for SWDs but for all students regardless of, for example, gender identity and expression, ethnicity, and religion. In that case, PETs likely need to broaden the curriculum and re-think about teaching and learning to respond to the heterogeneity that characterises different student groups (Penney et al., 2018). In doing so, Penney et al. (2018) emphasise the importance of shared decisionmaking and stress that:

$[\mathrm{R}] \mathrm{e}$-visioning inclusive practice must start with a willingness to engage in coconstructing curriculum with students and a focus on facilitating students' individual progress and growth through supported student-led learning that is 
characterised by choice and collaborative learning opportunities and that therefore, embraces personal relevance (p. 1072).

It is, furthermore, important to acknowledge that there are, albeit to a lesser extent, also some positive findings in the previous reviews. For example, some SWDs have reported opportunities for full and legitimate participation, and that they have experienced positive social peer interactions in integrated PE (Haegele \& Sutherland, 2015; Qi \& Ha, 2012; Rekaa et al., 2019). In their review, Rekaa et al. (2019) also recognised that more recent studies tended to demonstrate positive experiences among SWDs who were integrated into PE. However, some researchers have published their studies during the last few years, and have not yet been included in any review. From these studies, SWDs continue to experience restricted participation, and that integrated PE is perceived as an unpleasant environment that disregards their needs and interests (e.g., Tanure Alves, Grenier, Haegele, \& Duarte, 2020; Wang, 2019).

From a teacher perspective, it seems that many researchers have focused on attitudes and not necessarily their experiences from actually delivering integrated PE (e.g., Hutzler et al., 2019; Rekaa et al., 2019). It remains, however, unclear if attitudes translate into actual behaviours among PETs. There are several factors that make integrated PE challenging, such as feelings of being unprepared, and lack of confidence, comfortability and knowledge. Similar to this, a recent study from Europe showed that challenge emerged as a concern among PETs (McGrath, Crawford, \& O'Sullivan, 2019). In this study, the PETs particularly perceived that there was a lack of particularly hands-on praxis in their initial teacher education.

Concerning this teacher training, Tant and Watelain (2016) proposed three types of formal training that might facilitate inclusive practices in integrated PE: Didactic disciplinary training (e.g., adoption of sports activities and usage of an inclusive teaching style to allow for all students to participate in activities appropriate for different skill-level), pedagogical disciplinary training (e.g., creating opportunities for students to focus on their own learning process and using cooperative learning and peer tutoring to facilitate social relationships and increase learning among students), and multidisciplinary training (e.g., framing inclusive practice as teamwork where PETs and other stakeholders cooperate in gathering information and defining an individual inclusion strategy). Although these suggestions on formal training seem as logical as relevant, Pocock and Miyahara (2018) found that adoption of teaching practices seem to evolve as PETs embody inclusion and "strive to create a physically, psychologically and socially safe environment for all students - often without formal training“ (p. 761). Rather than being the result of formal training, the authors interpreted such inherent desire to facilitate inclusive PE as an expression of "moral imperative" to transform the contemporary PE culture. Furthermore, based on data collected from one PET as part of a critical participatory action research project, Petrie, Devcich, and Fitzgerald (2018) suggested that a multi-layered approach including a combination of actions, such as becoming a reflexive practitioner and reconsider what constitutes learning, might be required to facilitate inclusive PE. The authors, furthermore, stress that willingness and open-mindedness might outweigh knowledge regarding disabilities. In addition, that, similar to above, the curriculum and teaching practices should be viewed as a shared endeavour where SWDs should have opportunities to express their opinions and to be heard.

In terms of future research, perhaps the most critical question that arises from this umbrella review is how integrated PE can be adopted to reduce negative experiences and provide positive and meaningful experiences among all students. Here, the perspectives of 
students become essential (see, e.g., Vickerman, 2012) since their feelings, beliefs, and perceptions might differ from those of other stakeholders. It should be acknowledged that relatively few studies have focused on a student perspective. For example, Wilhelmsen and Sørensen (2017) reviewed 112 studies, of which six and two focused on the perspectives of SWDs and SWODs, respectively. Researchers are, therefore, encouraged to continue exploring integrated PE among students with various disabilities by, for example, using interviews, ethnographic observations and participatory research designs. In doing so, researchers should approach consultation with an open mind and flexibility to engage and empower students. Rather than engaging only those who already can access conventional research methods, researchers should strive to provide all SWDs, including those with severe disabilities, with the opportunity to participate by considering innovative methodological approaches to meet specific needs, skills, and abilities (see Coates \& Vickerman, 2013 for an extensive discussion).

Similar to the above, future studies among PETs should explore strategies for bridging challenges and creating opportunities for positive and meaningful experiences among all students who are integrated into PE. To create such opportunities requires, almost certainly, more than just adopting sports activities. Rather, this requires PETs to be open-minded and negotiate and broaden the curriculum and definition of ability in contemporary PE. In addition, to have confidence and knowledge to respond to the heterogeneity that characterises different student groups.

This paper is not without its limitations. Although it was assumed that reviews published over the past ten years would include both older and newer research, a limitation is that only those reviews published between 2010 and 2020 were included. Another limitation is that only English-language reviews were included.

\section{Perspectives}

This umbrella review synthesised findings from reviews published between 2010 and 2020 with different focuses and analytical procedures to obtain a comprehensive picture of the literature regarding the integration of SWDs in PE. From the reviews, to some degree, SWDs, SWODs and PETs have mixed experiences from and ambiguous attitudes towards the integration of SWDs in PE. At the same time, however, the experiences seem mostly negative from the viewpoints of SWDs and the effectiveness of integrated PE to meet inclusion agendas seems to be somewhat questionable.

Moreover, the possibility of generalisation might be limited because of study heterogeneity. Research regarding the integration of SWDs in PE has been conducted in different countries and contexts, with different research designs, through different perspectives, and with students from different disability categories. These factors should be considered when interpreting the findings as there, for example, might be inter-cultural differences in perceptions towards integration and inclusion of SWDs in PE. In addition, most studies have been conducted in North America and Europe, and it is unclear whether the knowledge generated can be translated to other countries and contexts.

Supplementary Materials: Appendix Table A. Electronic database and search strings; Appendix Table B. The methodological quality of the reviews.

Author Contributions: Conceptualisation, AF; Methodology, AF; Formal Analysis, AF; Writing-Original Draft Preparation, AF; Writing-Review \& Editing, AF.

Author affiliations:

1 Department of Food and Nutrition, and Sport Science, University of Gothenburg, Sweden.

* Correspondence: Andreas Fröberg; andreas.froberg@gu.se; Tel.: +46(o)317862149

Funding: This research received no external funding. 
Acknowledgements: The author gratefully acknowledges David Kjellin and Sofia Gullstrand, librarians, Social Sciences Libraries, University of Gothenburg, for their generous assistance in developing the search strings used in the electronic databases. The author also acknowledges the referees for their valuable comments and suggestions that have significantly improved this paper.

Conflicts of Interest: The author declares no conflict of interest.

Appendix A

Appendix Table A. Electronic database and search strings

\begin{tabular}{|c|c|}
\hline $\begin{array}{l}\text { Electronic } \\
\text { database }\end{array}$ & i string (performed 2020-02-06) \\
\hline $\begin{array}{l}\text { Educational } \\
\text { research } \\
\text { complete }\end{array}$ & $\begin{array}{l}\text { ( ((child* OR student* OR pupil*) N3 ("special need*" OR disab*)) OR } \\
\text { ("inclusive education") ) AND ( (meta-analys* OR metanalys* OR metasynthes* } \\
\text { OR meta-synthes* OR meta-aggregation* OR metaaggregation* OR meta- } \\
\text { ethnograph* OR metaethnograph* OR meta-interpretation* OR metainterpretation* } \\
\text { OR meta-stud* OR metastud* OR meta-theor* OR metatheor* OR meta-summar* } \\
\text { OR metasummar*) OR (review* OR synthes* OR map*) OR ("scoping stud*")) } \\
\text { AND ("physical education" OR PE ) }\end{array}$ \\
\hline Eric & $\begin{array}{l}\text { ( ((child* OR student* OR pupil*) N3 ("special need*" OR disab*)) OR } \\
\text { ("inclusive education") ) AND ( (meta-analys* OR metanalys* OR metasynthes* } \\
\text { OR meta-synthes* OR meta-aggregation* OR metaaggregation* OR meta- } \\
\text { ethnograph* OR metaethnograph* OR meta-interpretation* OR metainterpretation* } \\
\text { OR meta-stud* OR metastud* OR meta-theor* OR metatheor* OR meta-summar* } \\
\text { OR metasummar*) OR (review* OR synthes* OR map*) OR ("scoping stud*") ) } \\
\text { AND ("physical education" OR PE ) }\end{array}$ \\
\hline Scopus & $\begin{array}{l}\text { TITLE-ABS-KEY ( ( (meta-analys* OR metanalys* OR metasynthes* OR meta- } \\
\text { synthes* OR meta-aggregation* OR metaaggregation* OR meta-ethnograph* OR } \\
\text { metaethnograph* OR meta-interpretation* OR metainterpretation* OR meta-stud* } \\
\text { OR metastud* OR meta-theor* OR metatheor* OR meta-summar* OR } \\
\text { metasummar*) OR (review* OR synthes* OR map*) OR ("scoping } \\
\text { stud*") ) AND ( ( ( child* OR student* OR pupil*) W/3 ("special } \\
\text { need*" OR disab*) ) OR ("inclusive education")) AND ("physical } \\
\text { education" OR per ) ) AND NOT INDEX ( medline ) AND ( LIMIT- } \\
\text { TO (PUBYEAR, 2020) OR LIMIT-TO ( PUBYEAR, 2019) OR LIMIT- } \\
\text { TO (PUBYEAR, 2018) OR LIMIT-TO ( PUBYEAR, 2017) OR LIMIT- } \\
\text { TO (PUBYEAR, 2016) OR LIMIT-TO ( PUBYEAR, 2015) OR LIMIT- } \\
\text { TO (PUBYEAR, 2014) OR LIMIT-TO ( PUBYEAR, 2013) OR LIMIT- } \\
\text { TO (PUBYEAR, 2012) OR LIMIT-TO ( PUBYEAR, 2011) OR LIMIT- } \\
\text { TO (PUBYEAR, 2010)) }\end{array}$ \\
\hline scus & $\begin{array}{l}\text { ( ((child* OR student* OR pupil*) N3 ("special need*" OR disab*)) OR } \\
\text { ("inclusive education") ) AND ( (meta-analys* OR metanalys* OR metasynthes* } \\
\text { OR meta-synthes* OR meta-aggregation* OR metaaggregation* OR meta- } \\
\text { ethnograph* OR metaethnograph* OR meta-interpretation* OR metainterpretation* } \\
\text { OR meta-stud* OR metastud* OR meta-theor* OR metatheor* OR meta-summar* } \\
\text { OR metasummar*) OR (review* OR synthes* OR map*) OR ("scoping stud*")) } \\
\text { AND ("physical education" OR PE) }\end{array}$ \\
\hline
\end{tabular}




\section{Appendix B}

Appendix Table B. The methodological quality of the reviews

\begin{tabular}{|c|c|c|c|c|c|c|c|c|c|c|c|}
\hline \multirow[b]{2}{*}{ Citation details } & \multicolumn{10}{|c|}{ Items* } & \multirow[b]{2}{*}{ Total } \\
\hline & 1 & 2 & 3 & 4 & 5 & 6 & 7 & 8 & 9 & 10 & \\
\hline Haegele \& Sutherland (2015) & $\mathrm{Y}$ & Y & Y & Y & $\mathrm{N}$ & $\mathrm{N}$ & Y & $\mathrm{N}$ & Y & $\mathrm{Y}$ & 7 \\
\hline Hutzler et al. (2019) & $\mathrm{Y}$ & Y & Y & Y & $\mathrm{N}$ & $\mathrm{N}$ & Y & $\mathrm{N}$ & Y & $\mathrm{Y}$ & 7 \\
\hline Pocock \& Miyahara (2018) & $\mathrm{Y}$ & Y & Y & Y & $\mathrm{N}$ & $\mathrm{N}$ & Y & $\mathrm{N}$ & Y & $\mathrm{Y}$ & 7 \\
\hline Qi \& Ha (2012) & $\mathrm{Y}$ & Y & Y & Y & $\mathrm{N}$ & $\mathrm{N}$ & Y & $\mathrm{N}$ & Y & $\mathrm{Y}$ & 7 \\
\hline Rekaa et al. (2019) & $\mathrm{Y}$ & Y & Y & Y & $\mathrm{Y}$ & $\mathrm{N}$ & Y & $\mathrm{N}$ & Y & $\mathrm{Y}$ & 8 \\
\hline Ruscitti et al. (2017) & $\mathrm{Y}$ & Y & Y & Y & $\mathrm{Y}$ & $\mathrm{U}$ & Y & $\mathrm{N}$ & Y & $\mathrm{Y}$ & 8 \\
\hline Tant \& Watelain (2016) & $\mathrm{Y}$ & Y & Y & Y & $\mathrm{N}$ & $\mathrm{N}$ & Y & $\mathrm{N}$ & Y & $\mathrm{Y}$ & 7 \\
\hline Wilhelmsen \& Sørensen (2017) & $\mathrm{Y}$ & $\mathrm{Y}$ & Y & Y & $\mathrm{Y}$ & $\mathrm{U}$ & $\mathrm{Y}$ & $\mathrm{N}$ & $\mathrm{Y}$ & $\mathrm{Y}$ & 8 \\
\hline
\end{tabular}

Abbreviations: N, No; U, Unclear; Y, Yes.

${ }^{*}$ Critical appraisal checklist for systematic reviews and research syntheses according to the following ten items (Aromataris et al., 2015): 1) Is the review question clearly and explicitly stated? (note: a clearly and explicitly stated objective was accepted); 2) Were the inclusion criteria appropriate for the review question?; 3) Was the search strategy appropriate?; 4) Were the sources and resources used to search for studies adequate?; 5) Were the criteria for appraising studies appropriate? (note: the item was scored "no" if no criteria for appraising studies were used); 6) Was critical appraisal conducted by two or more reviewers independently? (note: the item was scored "no" if no criteria for appraising studies were used); 7) Were the methods used to combine studies appropriate? (note: an explicit description of method employed to synthesise the evidence was required); 8) Was the likelihood of publication bias assessed?; 9) Were recommendations for policy or practice supported by the reported data?; and 10) Were the specific directives for new research appropriate? Each item scored as either "Met” (1 point) or "Not met”, "Unclear", or "Not applicable" (o points each).

\section{References}

Aromataris, E., Fernandez, R., Godfrey, C. M., Holly, C., Khalil, H., \& Tungpunkom, P. (2015). Summarizing systematic reviews: Methodological development, conduct and reporting of an umbrella review approach. International Journal of Evidence-Based Healthcare, 13(3), 132-140. https://doi.org/10.1097/XEB.0000000000000055

Bailey, R. (2005). Evaluating the relationship between physical education, sport and social inclusion. Educational Review, 57(1), 71-90. https://doi.org/10.1080/0013191042000274196

Bailey, R., Armour, K., Kirk, D., Jess, M., Pickup, I., Sandford, R., \& BERA Physical Education and Sport Pedagogy Special Interest Group. (2009). The educational benefits claimed for physical education and school sport: An academic review.

Research Papers in Education, 24(1), 1-27. https://doi.org/10.1080/02671520701809817

Barber, W. (2018). Inclusive and accessible physical education: Rethinking ability and disability in pre-service teacher education. Sport, Education and Society, 23(6), 520532. https://doi.org/10.1080/13573.322.2016.1269004

Beni, S., Fletcher, T., \& Ní Chróinín, D. (2017). Meaningful experiences in physical education and youth sport: A review of the literature. Quest, 69(3), 291-312. https://doi.org/10.1080/00336297.2016.1224192

Block, M. E., \& Obrusnikova, I. (2007). Inclusion in physical education: A review of the literature from 1995-2005. Adapted Physical Activity Quarterly, 24(2), 103-124. https://doi.org/10.1123/apaq.24.2.103

Bronfenbrenner, U. (1979). The ecology of human development: Experiments by nature and design. Cambridge, MA: Harvard Univ. Press.

Bunbury, S. (2019). Unconscious bias and the medical model: How the social model may hold the key to transformative thinking about disability discrimination. International Journal of Discrimination and the Law, 19(1), 26-47. https://doi.org/10.1177/1358229118820742 
Coates, J., \& Vickerman, P. (2008). Let the children have their say: Children with special educational needs and their experiences of physical education - a review. Support for Learning, 23(4), 168-175. https://doi.org/10.1111/j.1467-9604.2008.00390.x

Coates, J., \& Vickerman, P. (2013). A review of methodological strategies for consulting children with special educational needs in physical education. European Journal of Special Needs Education, 28(3), 333-347.

https://doi.org/10.1080/08856257.2013.797705

Degener, T. (2016). Disability in a Human Rights Context. Laws (3), 35. https://doi.org/10.3390/laws5030035

Grant, M. J., \& Booth, A. (2009). A typology of reviews: An analysis of 14 review types and associated methodologies. Health Information and Libraries Journal, 26(2), 91-108. https://doi.org/10.1111/j.1471-1842.2009.00848.x

Grenier, M. (2007). Inclusion in physical education: From the medical model to social constructionism. Quest, 59(3), 298-310. https://doi.org/10.1080/00336297.2007.10483.554

Grenier, M. (2010). Moving to inclusion: A socio-cultural analysis of practice. International Journal of Inclusive Education, 14(4), 387-400. https://doi.org/10.1080/13603110802504598

Göransson, K., \& Nilholm, C. (2014). Conceptual diversities and empirical shortcomings a critical analysis of research on inclusive education. European Journal of Special Needs Education, 29(3), 265-280. https://doi.org/10.1080/08856257.2014.933545

Haegele, J. A. (2019). Inclusion illusion: Questioning the inclusiveness of integrated physical education. Quest, 71(4), 387-397. https://doi.org/10.1080/00336297.2019.1602547

Haegele, J. A., \& Hodge, S. (2016). Disability discourse: Overview and critiques of the medical and social models. Quest, 68(2), 193-206. https://doi.org/10.1080/00336297.2016.1143849

Haegele, J. A., \& Sutherland, S. (2015). Perspectives of students with disabilities toward physical education: A qualitative inquiry review. Quest, 67(3), 255-273. https://doi.org/10.1080/00336297.2015.1050118

Haug, P. (2017). Understanding inclusive education: Ideals and reality. Scandinavian Journal of Disability Research, 19(3), 206-217. http://doi.org/10.1080/15017419.2016.1224778

Hernández-Torrano, D., Somerton, M., \& Helmer, J. (2020). Mapping research on inclusive education since Salamanca Statement: A bibliometric review of the literature over 25 years. International Journal of Inclusive Education, 1-20. https://doi.org/10.1080/13603116.2020.17475.55

Hollis, J. L., Sutherland, R., Williams, A. J., Campbell, E., Nathan, N., Wolfenden, L., . . . Wiggers, J. (2017). A systematic review and meta-analysis of moderate-to-vigorous physical activity levels in secondary school physical education lessons. International Journal of Behavioral Nutrition and Physical Activity, 14(1), 52. https://doi.org/10.1186/s12966-017-0504-0

Hollis, J. L., Williams, A. J., Sutherland, R., Campbell, E., Nathan, N., Wolfenden, L., . . . Wiggers, J. (2016). A systematic review and meta-analysis of moderate-to-vigorous physical activity levels in elementary school physical education lessons. Preventive Medicine, 86, 34-54. https://doi.org/10.1016/j.ypmed.2015.11.018

Hutzler, Y., Meier, S., Reuker, S., \& Zitomer, M. (2019). Attitudes and self-efficacy of physical education teachers toward inclusion of children with disabilities: A narrative review of international literature. European Journal of Physical Education, 24(3), 249-266. https://doi.org/10.1080/17408989.2019.1571183

Levitt, J. M. (2017). Exploring how the social model of disability can be re-invigorated: In response to Mike Oliver. Disability \& Society, 32(4), 589-594. https://doi.org/10.1080/09687599.2017.1300390

McGrath, O., Crawford, S., \& O’Sullivan, D. (2019). 'It's a 'challenge': Post primary physical education teachers' experiences of and perspectives on inclusive practice with students 
with disabilities. European Journal of Adapted Physical Activity, 12(1), 2. https://doi.org/10.5507/euj.2018.011

Moher, D., Liberati, A., Tetzlaff, J., \& Altman, D. G. (2009). Preferred reporting items for systematic reviews and meta-analyses: The PRISMA statement. PLOS Medicine, 6(7). https://doi.org/10.1371/journal.pmed.1000097

Nabaskues-Lasheras, I., Usabiaga, O., Lozano-Sufrategui, L., Drew, K. J., \& Standal, Ø. F. (2019). Sociocultural processes of ability in physical education and physical education teacher education: A systematic review. European Physical Education Review, 26(4), 865-884. https://doi.org/10.1177/1356336X19891752

O’Brien, D., Kudláček, M., \& Howe, D. P. (2009). A contemporary review of English language literature on inclusion of students with disabilities in physical education: A European perspective. European Journal of Adapted Physical Activity, 2(1), 46-61. https://doi.org/10.5507/euj.2009.004

Oliver, M. (1983). Social work with disabled people. Basingstoke, UK: Macmillan.

Oliver, M. (1990). The politics of disablement. Basingstoke, UK: Macmillan.

Oliver, M. (2013). The social model of disability: Thirty years on. Disability \& Society, 28(7), 1024-1026. https://doi.org/10.1080/09687599.2013.818773

Opstoel, K., Chapelle, L., Prins, F. J., De Meester, A., Haerens, L., van Tartwijk, J., \& De Martelaer, K. (2019). Personal and social development in physical education and sports: A review study. European Physical Education Review, 26(4), 797-813. https://doi.org/10.1177/1356336X19882054

Patton, M. (2015). Qualitative research \& evaluation methods: Integrating theory and practice (4th ed.). Thousand Oaks, CA: Sage.

Peers, D., Spencer-Cavaliere, N., \& Eales, L. (2014). Say what you mean: Rethinking disability language in Adapted Physical Activity Quarterly. Adapted Physical Activity Quarterly, 31(3), 265-282. https://doi.org/10.1123/apaq.2013-0091

Penney, D., Jeanes, E., O’Connor, J., \& Alfrey, L. (2018) Re-theorising inclusion and reframing inclusive practice in physical education. International Journal of Inclusive Education, 22(10), 1062-1077. https://doi.org/10.1080/13603116.2017.1414888

Penney, D., \& Jess, M. (2004). Physical education and physically active lives: A lifelong approach to curriculum development. Sport, Education and Society, 9(2), 269-287. https://doi.org/10.1080/1357332042000233985

Petrie, K., Devcich, J., \& Fitzgerald, H. (2018). Working towards inclusive physical education in a primary school: 'Some days I just don't get it right'. Physical Education and Sport Pedagogy, 23(4), 345-357. https://doi.org/10.1080/17408989.2018.1441391

Pocock, T., \& Miyahara, M. (2018). Inclusion of students with disability in physical education: A qualitative meta-analysis. International Journal of Inclusive Education, 22(7), 751-766. https://doi.org/10.1080/13603116.2017.1412508

Qi, J., \& Ha, A. S. (2012). Inclusion in physical education: A review of literature. International Journal of Disability, Development and Education, 59(3), 257-281. https://doi.org/10.1080/1034912X.2012.697737

Rekaa, H., Hanisch, H., \& Ytterhus, B. (2019). Inclusion in physical education: Teacher attitudes and student experiences. A systematic review. International Journal of Disability, Development and Education, 66(1), 36-55. https://doi.org/10.1080/1034912X.2018.1435852

Ruscitti, R. J., Thomas, S. G., \& Bentley, D. C. (2017). The experiences of students without disabilities in inclusive physical education classrooms: A review of literature. AsiaPacific Journal of Health, Sport and Physical Education, 8(3), 245-257. https://doi.org/10.1080/18377122.2017.1345286

Slee, R. (2018). Defining the scope of inclusive education: Think piece prepared for the 2020 Global Education Monitoring Report Inclusion and Education. Paris: UNESCO. Retrieved from: https://unesdoc.unesco.org/ark:/48223/pfooo0265773

Smith, A., \& Thomas, N. (2006). Including pupils with special educational needs and disabilities in National Curriculum Physical Education: A brief review. European 
Journal of Special Needs Education, 21(1), 69-83.

https://doi.org/10.1080/08856250500491849

Spencer-Cavaliere, N., \& Watkinson, E. J. (2010). Inclusion understood from the perspectives of children with disability. Adapted Physical Activity Quarterly, 27(4), 275-293. https://doi.org/10.1123/apaq.27.4.275

Stern, C., Jordan, Z., \& McArthur, A. (2014). Developing the review question and inclusion criteria. American Journal of Nursing, 114(4), 53-56.

https://doi.org/10.1097/01.NAJ.0000445689.67800.86

Sutton, A., Clowes, M., Preston, L., \& Booth, A. (2019). Meeting the review family: Exploring review types and associated information retrieval requirements. Health Information \& Libraries Journal, 36(3), 202-222. https://doi.org/10.1111/hir.12276

Tant, M., \& Watelain, E. (2016). Forty years later, a systematic literature review on inclusion in physical education (1975-2015): A teacher perspective. Educational Research Review, 19, 1-17. https://doi.org/10.1016/j.edurev.2016.04.002

Tanure Alves, M. L., Grenier, M., Haegele, J. A., \& Duarte, E. (2020). 'I didn't do anything, I just watched': perspectives of Brazilian students with physical disabilities toward physical education. International Journal of Inclusive Education, 24(10), 1129-1142. https://doi.org/10.1080/13603116.2018.1511760

Tinning, R. (2012). The idea of physical education: A memetic perspective. Physical Education \& Sport Pedagogy, 17(2), 115-126. https://doi.org/10.1080/17408989.2011.582488

United Nations. (2015). Transforming our world: The 2030 Agenda for Sustainable Development. Retrieved from: https://sustainabledevelopment.un.org/

United Nations Educational, Scientific and Cultural Organization. (2008). International conference on education, 48th session, Geneva, 25-28 November, 20o8: Final report. Retrieved from:

http://www.ibe.unesco.org/fileadmin/user upload/Policy Dialogue/48th ICE/ICE FINAL REPORT eng.pdf

UNESCO. (2015). Quality Physical Education Guidelines for Policy-makers. Paris: United Nations Educational, Scientific and Cultural Organization. Retrieved from: http://unesdoc.unesco.org/images/0023/002311/231101E.pdf

UNESCO. (2020). Global Education Monitoring Report 2020: Inclusion and education: All means all. Paris, United Nations Educational, Scientific and Cultural Organization. Retrieved from: https://unesdoc.unesco.org/ark:/48223/pfooo0373718.locale=en

Van Mieghem, A., Verschueren, K., Petry, K., \& Struyf, E. (2018). An analysis of research on inclusive education: A systematic search and meta review. International Journal of Inclusive Education, 1-15. https://doi.org/10.1080/13603116.2018.1482012

Vickerman, P. (2012). Including children with special educational needs in physical education: Has entitlement and accessibility been realised? Disability \& Society, 27(2), 249-262. https://doi.org/10.1080/09687599.2011.644934

Wang, L. (2019). Perspectives of students with special needs on inclusion in general physical education: A social-relational model of disability. Adapted Physical Activity Quarterly, 36(2), 242-263. https://doi.org/10.1123/apaq.2018-0068

Ward, P. \& Lee, M-A. (2005). Peer-assisted learning in physical education: A review of theory and research. Journal of Teaching in Physical Education, 24(3), 205-225. https://doi.org/10.1123/itpe.24.3.205

Wilhelmsen, T., \& Sørensen, M. (2017). Inclusion of children with disabilities in physical education: A systematic review of literature from 2009 to 2015. Adapted Physical Activity Quarterly, 34(3), 311-337. https://doi.org/10.1123/apaq.2016-0017

World Health Organization. (2015). WHO global disability action plan 2014-2021. Better health for all people with disability. Geneva: World Health Organization. Retrieved from: https://www.who.int/disabilities/actionplan/en/

(C) 2021 by the authors. Submitted for possible open access publication under the terms and conditions of the Creative Commons Attribution (CC BY) license

(http://creativecommons.org/licenses/by/4.o/). 